\title{
FLORA ARBÓREA DA ARBORIZAÇÃO URBANA DA CIDADE DE PARANAGUÁ, PARANÁ, BRASIL
}

\author{
ARBOREAL FLORA OF THE URBAN AFFORESTATION IN THE MUNICIPALITY OF \\ PARANAGUÁ, PARANÁ, BRAZIL
}

\author{
Rodolfo de Almeida Bonaldi ${ }^{1}$ e lonete Hasse ${ }^{2}$
}

\begin{abstract}
RESUMO
O presente trabalho teve como objetivo registrar as espécies que ocorrem na arborização urbana do município de Paranaguá, comparar dois métodos de distribuição de espécies, sendo um abrangendo fronteiras políticas e o outro critério ecológico, e indicar as espécies exóticas invasoras. A amostragem foi realizada através de saídas de campo, percorrendo ruas, praças e parques, em uma área que corresponde 19\% (18 $\left.\mathrm{km}^{2}\right)$ da área urbana da cidade. Os dados de campo foram coletados com auxílio de uma prancheta e caneta, sendo anotado o nome científico de cada espécie. Foram incluídas para o levantamento todas as espécies arbóreas, arbustivas e rizomatosas. As espécies foram classificadas de acordo com distribuição geográfica por fronteiras políticas e por critério ecológico e indicada as espécies exóticas invasoras. Foram registradas 198 espécies, pertencentes a 153 gêneros, enquadradas em 63 famílias. O método para classificação das espécies para distribuição geográfica por fronteira política indicou que $56 \%$ são espécies exóticas, e o método por critério ecológico indicou que $78 \%$ são espécies exóticas. Do total das 198 espécies registradas, 24 espécies são exóticas invasoras para o estado do Paraná. A cidade de Paranaguá, como inúmeras cidades do Brasil, registrou elevado número de espécies exóticas na arborização urbana.
\end{abstract}

Palavras-chave: Espécies exóticas; Espécies nativas; Plantas invasoras.

\begin{abstract}
This study aimed to record the species that occur in urban afforestation of the municipality of Paranaguá, compare two types of distribution methods, one covering political boundaries and other based on ecological criteria, and indicate the invasive alien species. Sampling was performed on field trips thought streets, squares and parks, in an area corresponding to $19 \%\left(18 \mathrm{~km}^{2}\right)$ of the urban area of the city. Field data were collected with a drawing board and pen, and the scientific name of each species was written. For the survey, it was included all trees, shrubs and rhizomatous species. The species were classified according to geographical distribution by political frontier and ecological criterion and it was indicated the invasive alien species. There were recorded 198 species belonging to 153 genera distributed into 63 families. The method for species classification of geographical distribution by political frontier indicated $56 \%$ of exotic species, and the method by ecological criterion indicated $78 \%$ of exotic species. Of the total of 198 species, 24 species are invasive alien to the state of Paraná. The municipality of Paranaguá, as many cities in Brazil, recorded high number of alien species in urban afforestation.
\end{abstract}

Keywords: Exotic alien species; Native species; Invasive plants.

Recebido em 12.09.2016 e aceito em 12.12.2016

1 Biólogo, Mestre em Ecologia e Conservação, UFPR, Campus Centro Politécnico, Curitiba/PR. Email: rbbonaldi@gmail.com

2 Bióloga, Dr., Professora do Instituto Federal do Paraná (IFPR), Campus Paranaguá/PR. Email: ionete.hasse@ifpr.edu.br 


\section{INTRODUÇÃO}

A arborização urbana é um elemento de relevante importância para a obtenção de níveis satisfatórios de qualidade de vida (FARIA; MONTEIRO; FISCH, 2007), pois reduzem o calor, a poluição atmosférica e sonora, diminuem a velocidade dos ventos, produzem sombra, captam e drenam água evitando enchentes, contribuem para a formação das nuvens, embelezam ruas, canteiros, praças e jardins, protegem o solo, e atraem a avifauna (SILVA; SILVEIRA; TEIXEIRA, 2008).

No entanto, a arborização urbana não é isenta de conflitos, pois a substituição das espécies nativas por espécies exóticas pode gerar problemas, alterando o ambiente natural, diminuindo a biodiversidade das áreas urbanas, criando ambientes urbanos uniformizados com as mesmas espécies exóticas em diferentes cidades (MACHADO et al., 2006), podendo também causar introdução de espécies exóticas invasoras. A falta de planejamento da arborização pode acarretar em conflito com a estrutura urbana (FERRO et al., 2015), tais como fiações elétricas, encanamentos, calhas, calçamentos, muros, postes de iluminação e sinalização (SANTOS et al., 2015), que consequentemente pode ocasionar prejuízos econômicos.

Segundo IUCN (2016), as espécies exóticas são definidas como uma espécie, subespécie ou menor táxon ocorrendo fora da sua área natural, tendo como interferência proposital ou acidental realizado por atividades vinculadas aos seres humanos, incluindo qualquer parte do organismo que possa sobreviver e com isso se reproduzir. É uma das principais ameaças para perda de diversidade biológica, influenciando diretamente no declínio da biodiversidade, pois causam impactos de grande proporção e geralmente irreversível, influenciam nas relações ecológicas e extinguem espécies nativas, geram problemas econômicos (controle, manejo, queda de produção), são registradas em todos os grupos taxonômicos.

Diversos fatores podem estar relacionados com a introdução de espécies exóticas na arborização urbana, tais como à falta de informações sobre a flora brasileira e seu potencial paisagístico (SILVA; PERELLÓ, 2010), vantagens competitivas em relação às espécies nativas, estando livres de competidores, predadores e parasitas (INSTITUTO HORUS, 2016a). Outro fator que contribui com a disseminação de espécies exóticas, é falta de preocupação das prefeituras com o planejamento da arborização, com isso, os próprios moradores executam o plantio em locais públicos (SILVA; SILVEIRA; TEIXEIRA, 2008).

O presente trabalho teve como objetivo registrar as espécies que ocorrem na arborização urbana (arborização de ruas, praças e parques) da cidade de Paranaguá, 
comparar dois métodos de distribuição geográfica de espécies, sendo um abrangendo fronteiras políticas e o outro critério ecológico, e indicar as espécies exóticas invasoras.

\section{MATERIAL E MÉTODOS}

\section{Área de estudo}

O trabalho foi realizado na cidade de Paranaguá, no estado do Paraná, que está localizada há 90 quilômetros da capital paranaense, entre as coordenadas $25^{\circ} 31^{\prime \prime} 12^{\prime \prime}$ e 48³0'32", há 5 metros sob o nível do mar, possuindo uma área territorial de 826,225km².

Paranaguá, segundo a classificação climática de Köeppen, o clima é do tipo Cfa, clima subtropical, com temperatura média no mês mais frio inferior a $18{ }^{\circ} \mathrm{C}$ (mesotérmico) e temperatura média no mês mais quente acima de $22^{\circ} \mathrm{C}$, com verões quentes, geadas pouco frequentes e tendência de concentração das chuvas nos meses de verão, sem estação seca definida (IAPAR, 2016).

A média anual de temperatura varia entre 20 e $21^{\circ} \mathrm{C}$, sendo a média de temperaturas máximas de 26 a $27^{\circ} \mathrm{C}$ e das mínimas de 16 a $17^{\circ} \mathrm{C}$. Nos meses menos chuvosos (junho, julho, agosto), a precipitação varia de 250 a $350 \mathrm{~mm}$, e nos meses mais chuvosos (dezembro, janeiro e fevereiro) a precipitação varia de 700 a $800 \mathrm{~mm}$, registrando uma média anual de 2000 a 2500. Com relação à umidade relativa do ar, a média anual varia de 80 a $85 \%$ (IAPAR, 2016).

Paranaguá está dentro da área de ocorrência do Bioma Mata Atlântica, sendo a área de estudo, o meio urbano, apresenta predomínio da unidade Fitogeográfica da Floresta Ombrófila Densa das Terras Baixas e Formação Pioneira Influência Marinha (Restinga), porém estas duas formações vegetacionais atualmente encontram-se degradadas devido à urbanização.

O trabalho foi realizado na área aproximada de $18 \mathrm{~km}^{2}$ (Figura 1), a qual corresponde cerca de $19 \%\left(95,15 \mathrm{~km}^{2}\right)$ da área urbana da cidade de Paranaguá. A escolha da área destacada em azul na Figura 1 justifica pelo fato de apresentar grande fluxo de pessoas, por apresentar maior densidade demográfica e pela influência econômica que exerce sobre a cidade de Paranaguá. 

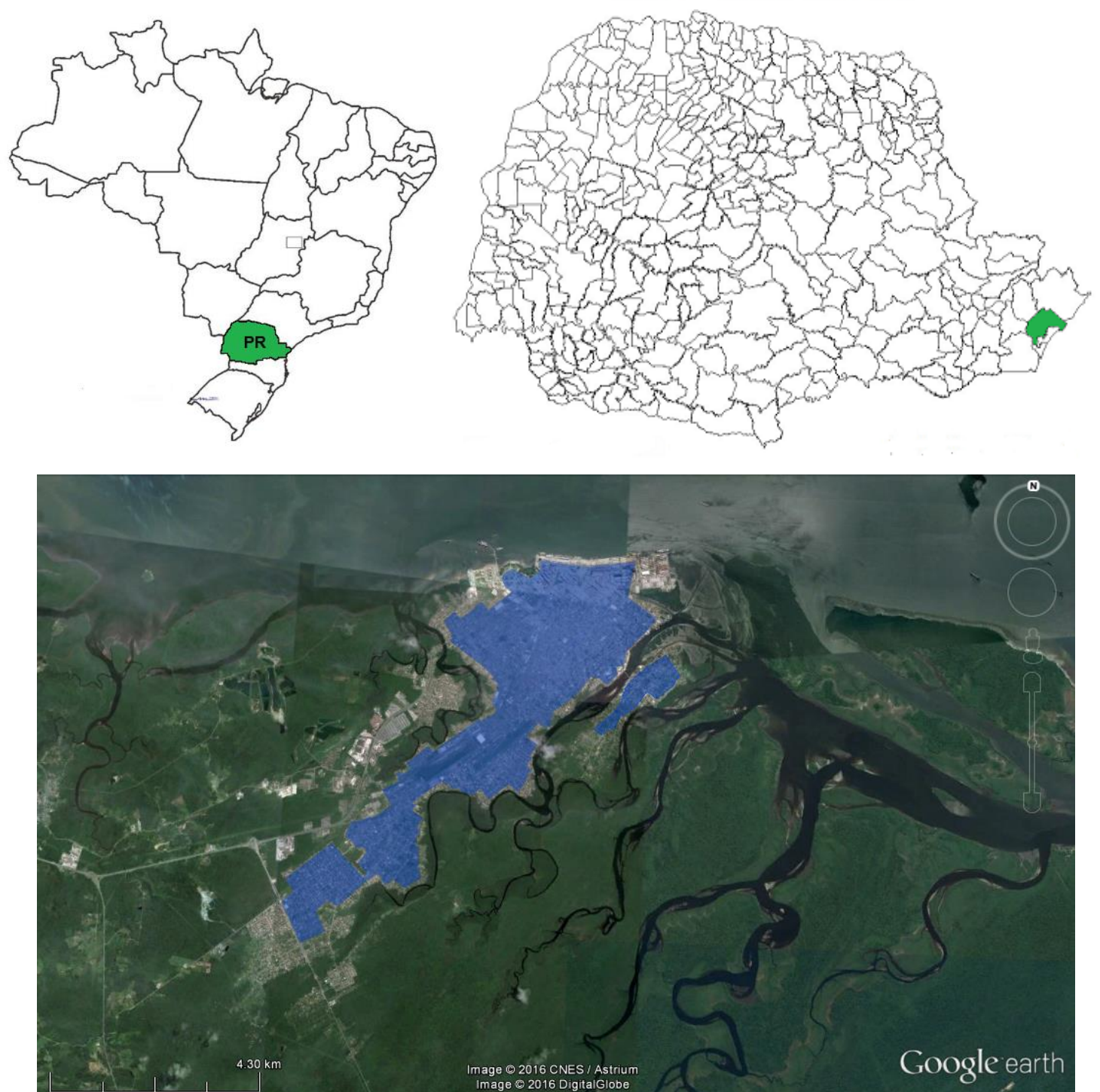

Figura 1. Área de estudo: a cor azul indica a área aproximada de $18 \mathrm{~km}^{2}$ que foi percorrida para o levantamento do presente estudo no município de Paranaguá

Figure 1. Study area: the blue color indicates the approximate area of $18 \mathrm{~km}^{2}$ which was sampled for sampling this study in the municipality of Paranaguá

\section{Procedimentos metodológicos}

A amostragem foi realizada através de saídas de campo, percorrendo ruas, praças e parques conforme demonstrado na Figura 1. A coleta de dados de campo foi realizada com auxílio de uma prancheta e caneta, sendo anotado o nome científico de cada espécie. Quando não conseguiu identificar a espécie em campo, foram realizados registros fotográficos e coleta de material para posterior identificação através de comparação de exsicatas em herbários (HUCP - Herbário da Pontifícia Universidade Católica do Paraná e MBM - Museu Botânico Municipal de Curitiba) e consulta a bibliografia especializada. Foram incluídas para o levantamento todas as espécies arbóreas, arbustivas e rizomatosas (palmeira). 
As espécies foram classificadas por dois métodos: o primeiro de acordo com distribuição geográfica por fronteiras políticas, normalmente utilizadas por diversos trabalhos que abordam arborização, tais como Kramer e Krupek (2012), Ferro et al. (2015), Lima Neto et al. (2016) e o segundo método utilizado para a classificação da distribuição geográfica foi por meio de critério ecológico, sendo dividido em quatro categorias, tendo como base a vegetação que cobre a cidade de Paranaguá (adaptado BLUM; BORGO; SAMPAIO, 2008): 1) Nativa (Nat) - espécie que ocorre na unidade fitogeográfica Floresta Ombrófila Densa das Terras Baixas e Formações pioneiras típicas da Planície do litoral do Paraná; 2) Exótica Extra Ecossistema de Floresta Ombrófila Densa das Terras Baixas e Formações Pioneiras (Ex-NAT) - espécies que ocorrem em outras unidades fitogeográficas que ocorrem no Paraná, mas que não ocorrem nos limites citados para o critério ecológico definido para espécies nativas, exemplo: Floresta Ombrófila Densa Submontana, Montana e Altomontana; Floresta Ombrófila Mista, Floresta Estacional Semidecidual e Cerrado; 3) Exótica Extra Ecossistema Paranaenses (Ex-PR) espécie que não possui distribuição geográfica em ecossistemas paranaenses, exemplo: Amazônia, Caatinga, Pampa e Pantanal; 4) Exótica Extra Ecossistemas Brasileiros (Ex-BR) espécie que não possui distribuição geográfica em ecossistemas brasileiros.

Para classificar as espécies de acordo com as quatro categorias citadas anteriormente, foram consultados artigos locais, guias de identificação e os sites da JBRJ (2016) e The Plant List (2016).

Para a classificação das plantas Angiospermas e Gymnospermas foram consultados o sistema APG III (Angiosperm Phylogeny Group, 2009). Para verificação da grafia correta os binômios, foram consultados: JBRJ (2016) e The Plant List (2016).

Para indicação das espécies exóticas invasoras registradas no presente estudo, foi consultada a Portaria IAP no 59 de 15 de abril de 2015 - "Lista de Espécies Exóticas Invasoras do Estado do Paraná" (IAP, 2016) e o banco de dados do Instituto Horus (2016b).

\section{RESULTADOS E DISCUSSÃO}

Foram registradas 198 espécies (Tabela 1), pertencentes a 153 gêneros, enquadradas em 63 famílias. Deste total, 8 espécies são gimnospermas e o restante, 190 espécies são angiospermas. 
Tabela 1. Espécies registradas na arborização urbana no município de Paranaguá-PR-Brasil

Table 1. Species recorded in urban afforestation in the municipality of Paranaguá- PR - Brazil

\begin{tabular}{|c|c|c|c|}
\hline $\begin{array}{l}\text { FAMILIA (no de espécies) } \\
\text { Espécie }\end{array}$ & Nome Popular & DGFP & DGCE \\
\hline $\begin{array}{l}\text { ACANTHACEAE (1) } \\
\text { Thunbergia erecta (Benth.) T. Anderson }\end{array}$ & anto-de-rei & Ex & Ex-BR \\
\hline $\begin{array}{l}\text { ADOXACEAE (2) } \\
\text { Sambucus australis Cham. \& Schltdl } \\
\text { Viburnum tinus } \mathrm{L} \text {. }\end{array}$ & $\begin{array}{l}\text { Sabugueiro } \\
\text { Lourotino }\end{array}$ & $\begin{array}{l}\text { Nat } \\
\text { Ex }\end{array}$ & $\begin{array}{l}\text { Ex-nat } \\
\text { Ex-BR }\end{array}$ \\
\hline $\begin{array}{l}\text { ANARCADIACEAE (5) } \\
\text { Anarcadium occindetale L. } \\
\text { Mangifera indica L. * } \\
\text { Schinnus molle L. } \\
\text { Schinus terebinthifolius Raddi } \\
\text { Spondias venulosa (Engl.) Engl. }\end{array}$ & $\begin{array}{l}\text { Caju } \\
\text { Manga } \\
\text { Aroeira-salsa } \\
\text { Aroeira } \\
\text { Cajá }\end{array}$ & $\begin{array}{l}\text { Nat } \\
\text { Ex } \\
\text { Nat } \\
\text { Nat } \\
\text { Nat }\end{array}$ & $\begin{array}{l}\text { Ex-PR } \\
\text { Ex-BR } \\
\text { Ex-nat } \\
\text { Nativa } \\
\text { Ex-PR }\end{array}$ \\
\hline $\begin{array}{l}\text { ANNONACEAE (4) } \\
\text { Anonna glabra L. } \\
\text { Annona mucosa Jacq. } \\
\text { Anonna muricata L. } \\
\text { Annona neosericea H.Rainer }\end{array}$ & $\begin{array}{l}\text { Araticum-do-brejo } \\
\text { Fruta-do-conde } \\
\text { Graviola } \\
\text { Pindaíba }\end{array}$ & $\begin{array}{l}\text { Nat } \\
\text { Nat } \\
\text { Ex } \\
\text { Nat }\end{array}$ & $\begin{array}{l}\text { Nat } \\
\text { Ex-PR } \\
\text { Ex-BR } \\
\text { Nativa }\end{array}$ \\
\hline $\begin{array}{l}\text { APOCYNACEAE (7) } \\
\text { Allamanda blanchetii A.DC. } \\
\text { Allamanda polyantha Müll. Arg. } \\
\text { Nerium oleander L. } \\
\text { Plumeria caracasana J. R. Johnst. } \\
\text { Plumeria nigra L. } \\
\text { Tabernaemontana divaricata (L.) R. Br. ex Roem. \& Schult. } \\
\text { Thevetia thevetioides (Kunth) K. Schum. }\end{array}$ & $\begin{array}{l}\text { Alamanda-rosa } \\
\text { Alamanda } \\
\text { Espirradeira } \\
\text { Jamim-manga-da-venezuela } \\
\text { Jasmim-manga } \\
\text { Jasmim-café } \\
\text { Chapéu-de-napoleão }\end{array}$ & $\begin{array}{l}\text { Nat } \\
\text { Nat } \\
\text { Ex } \\
\text { Ex } \\
\text { Ex } \\
\text { Ex } \\
\text { Ex }\end{array}$ & $\begin{array}{l}\text { Ex-PR } \\
\text { Ex-PR } \\
\text { Ex-BR } \\
\text { Ex-BR } \\
\text { Ex-BR } \\
\text { Ex-BR } \\
\text { Ex-BR }\end{array}$ \\
\hline $\begin{array}{l}\text { ARALIACEAE (4) } \\
\text { Polyscias guilfoylei (W. Bull) L.H. Bailey } \\
\text { Polyscias scutellaria (Burm. f.) Fosberg } \\
\text { Schefflera actinophylla (Endl.) Harms } \\
\text { Schefflera arboricola (Hayata) Merr. }{ }^{*}\end{array}$ & $\begin{array}{l}\text { Árvore-da-felicidade } \\
\text { Arália-redonda } \\
\text { Cheflera } \\
\text { Cheflera }\end{array}$ & $\begin{array}{l}\text { Ex } \\
\text { Ex } \\
\text { Ex } \\
\text { Ex }\end{array}$ & $\begin{array}{l}\text { Ex-BR } \\
\text { Ex-BR } \\
\text { Ex-BR } \\
\text { Ex-BR }\end{array}$ \\
\hline $\begin{array}{l}\text { ARAUCARIACEAE (2) } \\
\text { Araucaria angustifolia (Bertol.) Kuntze } \\
\text { Araucaria columnaris (G.Forst.) Hook. }\end{array}$ & & $\begin{array}{l}\text { Nat } \\
\text { Ex }\end{array}$ & \\
\hline $\begin{array}{l}\text { ARECACEAE (13) } \\
\text { Attalea dubia (Mart.) Burret } \\
\text { Archontophoenix cunninghamiana (H.Wendl.) H.Wendl. \& Drude } \\
\text { Bactris gasipaes Kunth } \\
\text { Cocos nucifera L. } \\
\text { Dypsis lutescens (H.Wendl.) Beentje \& J.Dransf. } \\
\text { Euterpe edulis Mart. } \\
\text { Euterpe oleracea Mart. } \\
\text { Licuala grandis H.Wendl. } \\
\text { Phoenix roebelenii O'Brien } \\
\text { Rhapis excelsa (Thunb.) Henry } \\
\text { Roystonea oleracea (Jacq.) O.F.Cook } \\
\text { Syagrus romanzoffiana (Cham.) Glassman } \\
\text { Trithrinax brasiliensis Mart. }\end{array}$ & $\begin{array}{l}\text { Indaiá } \\
\text { Palmeira real } \\
\text { Pupunha } \\
\text { Coqueiro } \\
\text { Palmeira-areca } \\
\text { Palmito jussara } \\
\text { Palmito açaí } \\
\text { Palmeira-leque-pequena } \\
\text { Palmeira-fénix } \\
\text { Palmeira-ráfia } \\
\text { Palmeira-imperial } \\
\text { Jerivá } \\
\text { Buriti-palito }\end{array}$ & $\begin{array}{l}\text { Nat } \\
\text { Ex } \\
\text { Nat } \\
\text { Nat } \\
\text { Ex } \\
\text { Nat } \\
\text { Nat } \\
\text { Ex } \\
\text { Ex } \\
\text { Ex } \\
\text { Ex } \\
\text { Nat } \\
\text { Nat }\end{array}$ & $\begin{array}{l}\text { Nat } \\
\text { Ex-BR } \\
\text { Ex-PR } \\
\text { Ex-PR } \\
\text { Ex-BR } \\
\text { Nativa } \\
\text { Ex-PR } \\
\text { Ex-BR } \\
\text { Ex-BR } \\
\text { Ex-BR } \\
\text { Ex-BR } \\
\text { Nat } \\
\text { Ex-PR }\end{array}$ \\
\hline $\begin{array}{l}\text { ASTERACEAE (4) } \\
\text { Helianthus annuus L. } \\
\text { Gymnanthemum amygdalinum (Delile) Sch. Bip. ex Walp. } \\
\text { Stifftia chrysantha J. C. Mikan } \\
\text { Vernonanthura beyrichii (Less.) H.Rob. }\end{array}$ & $\begin{array}{l}\text { Girassol } \\
\text { Figatil } \\
\text { Pau-cutia } \\
\text { Assa-peixe }\end{array}$ & $\begin{array}{l}\text { Ex } \\
\text { Ex } \\
\text { Nat } \\
\text { Nat }\end{array}$ & $\begin{array}{l}\text { Ex-BR } \\
\text { Ex-BR } \\
\text { Ex-Nat } \\
\text { Nat }\end{array}$ \\
\hline $\begin{array}{l}\text { BIGNONIACEAE (8) } \\
\text { Handroanthus albus (Cham.) Mattos } \\
\text { Handroanthus chrysotrichus (Mart. ex DC.) Mattos } \\
\text { Handroanthus heptaphyllus (Vell.) Mattos } \\
\text { Handroanthus umbellatus (Sond.) Mattos } \\
\text { Jacaranda mimosifolia D.Don } \\
\text { Jacaranda puberula Cham. } \\
\text { Spathodea campanulata P.Beauv. * } \\
\text { Tecoma stans (L.) Juss. ex Kunth * }\end{array}$ & $\begin{array}{l}\text { Ipê amarelo } \\
\text { lpê amarelo } \\
\text { lpê roxo } \\
\text { Ipê amarelo do brejo } \\
\text { jacaranda mimoso } \\
\text { Caroba } \\
\text { Espatódea } \\
\text { Ipê de jardim }\end{array}$ & $\begin{array}{l}\text { Nat } \\
\text { Nat } \\
\text { Nat } \\
\text { Nat } \\
\text { Ex } \\
\text { Nat } \\
\text { Ex } \\
\text { Ex }\end{array}$ & $\begin{array}{l}\text { Ex-Nat } \\
\text { Ex-Nat } \\
\text { Ex-Nat } \\
\text { Nat } \\
\text { Ex-BR } \\
\text { Nat } \\
\text { Ex-BR } \\
\text { Ex-BR }\end{array}$ \\
\hline
\end{tabular}




\begin{tabular}{|c|c|c|c|}
\hline $\begin{array}{l}\text { FAMILIA ( } n \text { o de espécies) } \\
\text { Espécie }\end{array}$ & Nome Popular & DGFP & DGCE \\
\hline $\begin{array}{l}\text { BIXACEAE (1) } \\
\text { Bixa orellana L. }\end{array}$ & Urucum & Nat & Ex-PR \\
\hline $\begin{array}{l}\text { BUXACEAE (1) } \\
\text { Buxus sempervirens L. }\end{array}$ & Buxinho & Ex & Ex-BR \\
\hline $\begin{array}{l}\text { CACTACEAE (2) } \\
\text { Nopalea cochenillifera (L.) Salm-Dyck } \\
\text { Opuntia monacantha Haw. }\end{array}$ & $\begin{array}{l}\text { Palma-doce } \\
\text { Palma-brava }\end{array}$ & $\begin{array}{l}\text { Ex } \\
\text { Nat }\end{array}$ & $\begin{array}{l}\text { Ex-BR } \\
\text { Nat }\end{array}$ \\
\hline $\begin{array}{l}\text { CANNABACEAE (1) } \\
\text { Trema micrantha (L.) Blume. }\end{array}$ & Pau-pólvora & Nat & Nat \\
\hline $\begin{array}{l}\text { CARICACEAE (1) } \\
\text { Carica papaya L. }\end{array}$ & Mamão & Ex & Ex-BR \\
\hline $\begin{array}{l}\text { CALOPHYLLACEAE (1) } \\
\text { Calophyllum brasiliense Cambess. }\end{array}$ & Guanandi & Nat & Nat \\
\hline $\begin{array}{l}\text { COMBRETACEAE (1) } \\
\text { Terminalia catappa L. * }\end{array}$ & Sombreiro & Ex & Ex-BR \\
\hline $\begin{array}{l}\text { CONVOLVULACEAE (1) } \\
\text { Ipomoea carnea Jacq. }\end{array}$ & Algodão-bravo & Nat & Ex-PR \\
\hline $\begin{array}{l}\text { CRYSOBALANACEAE (1) } \\
\text { Licania tomentosa (Benth.) Fritsch }\end{array}$ & Oiti & Nat & Ex-PR \\
\hline $\begin{array}{l}\text { CUPRESSACEAE (2) } \\
\text { Chamaecyparis obtusa (Siebold \& Zucc.) Endl. } \\
\text { Chamaecyparis pisifera (Siebold \& Zucc.) Endl. }\end{array}$ & $\begin{array}{l}\text { Cipreste } \\
\text { Tuia }\end{array}$ & $\begin{array}{l}\text { Ex } \\
\text { Ex }\end{array}$ & $\begin{array}{l}\text { Ex-BR } \\
\text { Ex-BR }\end{array}$ \\
\hline $\begin{array}{l}\text { CYCADACEAE (1) } \\
\text { Cycas circinalis L. }\end{array}$ & Cica & Ex & Ex-BR \\
\hline $\begin{array}{l}\text { DILLENIACEAE (1) } \\
\text { Dillenia indica } L .\end{array}$ & Árvore do dinheiro & Ex & Ex-BR \\
\hline $\begin{array}{l}\text { ELAEOCARPACEAE (1) } \\
\text { Elaeocarpus serratus L. }\end{array}$ & Azeitona-do-ceilão & Ex & Ex-BR \\
\hline $\begin{array}{l}\text { ERICACEAE (2) } \\
\text { Rhododendron simsii Planch. } \\
\text { Rhododendron thomsonii Hook. f. }\end{array}$ & $\begin{array}{l}\text { Azaléia } \\
\text { Rododendro }\end{array}$ & $\begin{array}{l}\text { Ex } \\
\text { Ex }\end{array}$ & $\begin{array}{l}\text { Ex-BR } \\
\text { Ex-BR }\end{array}$ \\
\hline $\begin{array}{l}\text { EUPHORBIACEAE (10) } \\
\text { Acalypha wilkesiana Müll. Arg. } \\
\text { Alchornea triplinervia (Spreng.) Müll.Arg. } \\
\text { Aleurites moluccanus (L.) Willd.* } \\
\text { Codiaeum variegatum (L.) Rumph. ex A. Juss. } \\
\text { Euphorbia cotinifolia L. } \\
\text { Euphorbia milii Des Moul. } \\
\text { Euphorbia pulcherrima Willd. ex Klotzsch } \\
\text { Euphorbia tirucalli L. } \\
\text { Manihot esculenta Crantz } \\
\text { Ricinus communis L. }{ }^{*}\end{array}$ & $\begin{array}{l}\text { Acalifa } \\
\text { Tapiá } \\
\text { Noz-da-índia } \\
\text { Folha-imperial } \\
\text { Barrabás } \\
\text { Coroa-de-espinho } \\
\text { Bico de papagaio } \\
\text { Avelós } \\
\text { Mandioca-brava } \\
\text { Mamona }\end{array}$ & $\begin{array}{l}\text { Ex } \\
\text { Nat } \\
\text { Ex } \\
\text { Ex } \\
\text { Ex } \\
\text { Ex } \\
\text { Ex } \\
\text { Ex } \\
\text { Nat } \\
\text { Ex }\end{array}$ & $\begin{array}{l}\text { Ex-BR } \\
\text { Nat } \\
\text { Ex-BR } \\
\text { Ex-BR } \\
\text { Ex-BR } \\
\text { Ex-BR } \\
\text { Ex-BR } \\
\text { Ex-BR } \\
\text { Ex-PR } \\
\text { Ex-BR }\end{array}$ \\
\hline $\begin{array}{l}\text { FABACEAE (30) } \\
\text { Albizia lebbeck (L.) Benth. } \\
\text { Anadenanthera colubrina (Vell.) Brenan } \\
\text { Andira anthelmia (Vell.) Benth. } \\
\text { Bauhinia forficata Link } \\
\text { Bauhinia variegata L. } \\
\text { Caesalpinia echinata Lam. } \\
\text { Caesalpinia pulcherrima (L.) Sw. } \\
\text { Cajanus cajan (L.) Huth } \\
\text { Calliandra brevipes Benth. } \\
\text { Cassia bakeriana Craib } \\
\text { Cassia fistula L. } \\
\text { Cassia leptophylla Vogel } \\
\text { Delonix regia (Hook.) Raf. } \\
\text { Erythrina speciosa Andrews } \\
\text { Hymenaea courbaril L. } \\
\text { Inga edulis Mart. } \\
\text { Leucaena leucocephala (Lam.) de Wit * } \\
\text { Libidibia ferrea (Mart. ex Tul.) L. P. Queiroz } \\
\text { Machaerium brasiliense Vogel } \\
\text { Mimosa bimucronata (DC.) Kuntze }\end{array}$ & $\begin{array}{l}\text { Albizia } \\
\text { Angico-branco } \\
\text { Jacarandá lombriga } \\
\text { Pata-de-vaca } \\
\text { Pata-de-vaca } \\
\text { Pau-brasil } \\
\text { Flamboianzinho } \\
\text { Guandu } \\
\text { Esponja } \\
\text { Cássia rósea } \\
\text { Cássia } \\
\text { Falso-barbatimão } \\
\text { Flamboyant } \\
\text { Molungu } \\
\text { Jatobá } \\
\text { Ingá } \\
\text { Leucena } \\
\text { Pau-ferro } \\
\text { Sapuva } \\
\text { Maricá }\end{array}$ & $\begin{array}{l}\text { Ex } \\
\text { Nat } \\
\text { Nat } \\
\text { Nat } \\
\text { Ex } \\
\text { Nat } \\
\text { Ex } \\
\text { Ex } \\
\text { Nat } \\
\text { Ex } \\
\text { Ex } \\
\text { Nat } \\
\text { Ex } \\
\text { Nat } \\
\text { Nat } \\
\text { Nat } \\
\text { Ex } \\
\text { Nat } \\
\text { Nat } \\
\text { Nat }\end{array}$ & $\begin{array}{l}\text { Ex-BR } \\
\text { Ex-Nat } \\
\text { Nat } \\
\text { Ex-Nat } \\
\text { Ex-BR } \\
\text { Ex-PR } \\
\text { Ex-BR } \\
\text { Ex-BR } \\
\text { Ex-Nat } \\
\text { Ex-BR } \\
\text { Ex-BR } \\
\text { Ex-Nat } \\
\text { Ex-BR } \\
\text { Nat } \\
\text { Ex-Nat } \\
\text { Nat } \\
\text { Ex-BR } \\
\text { Ex-PR } \\
\text { Nat } \\
\text { Nat }\end{array}$ \\
\hline
\end{tabular}




\begin{tabular}{|c|c|c|c|}
\hline $\begin{array}{l}\text { FAMILIA ( } n \text { o de espécies) } \\
\text { Espécie }\end{array}$ & Nome Popular & DGFP & DGCE \\
\hline $\begin{array}{l}\text { Parapiptadenia rigida (Benth.) Brenan } \\
\text { Pithecellobium dulce (Roxb.) Benth. } \\
\text { Poincianella pluviosa (DC.) L. P. Queiroz } \\
\text { Pterocarpus rohrii Vahl } \\
\text { Schizolobium parahyba (Vell.) Blake } \\
\text { Senna macranthera (DC. ex Collad.) H. S. Irwin \& Barneby * } \\
\text { Senna multijuga (Rich.) Irwin et Barn } \\
\text { Senna pendula (Humb.\& Bonpl. ex Willd.) H. S. Irwin \& Barneby } \\
\text { Tamarindus indica L. } \\
\text { Tipuana tipu (Benth.) Kuntze }\end{array}$ & $\begin{array}{l}\text { Angico-vermelho } \\
\text { Guamuchil } \\
\text { Sibipiruna } \\
\text { Sangueiro } \\
\text { Guapuruvu } \\
\text { Chuva-de-ouro } \\
\text { Aleluia } \\
\text { Amarelinha } \\
\text { Tamarindo } \\
\text { Tipuana }\end{array}$ & $\begin{array}{l}\text { Nat } \\
\text { Ex } \\
\text { Nat } \\
\text { Nat } \\
\text { Nat } \\
\text { Nat } \\
\text { Nat } \\
\text { Nat } \\
\text { Ex } \\
\text { Ex }\end{array}$ & $\begin{array}{l}\text { Ex-Nat } \\
\text { Ex-BR } \\
\text { Ex-PR } \\
\text { Nat } \\
\text { Nat } \\
\text { Ex-Nat } \\
\text { Nat } \\
\text { Nat } \\
\text { Ex-BR } \\
\text { Ex-BR }\end{array}$ \\
\hline $\begin{array}{l}\text { HYDRANGEACEAE (1) } \\
\text { Hydrangea macrophylla (Thunb.) Ser. }\end{array}$ & Hortência & Ex & Ex-BR \\
\hline $\begin{array}{l}\text { LAMIACEAE (2) } \\
\text { Ocimum basilicum } \mathrm{L} \text {. } \\
\text { Plectranthus barbatus Andrews }\end{array}$ & $\begin{array}{l}\text { Alfavaca } \\
\text { Falso-boldo }\end{array}$ & $\begin{array}{l}\text { Ex } \\
\text { Ex }\end{array}$ & $\begin{array}{l}\text { Ex-BR } \\
\text { Ex-BR }\end{array}$ \\
\hline $\begin{array}{l}\text { LAURACEAE (5) } \\
\text { Cinnamomum burmanni (Nees \& T. Nees) Blume } \\
\text { Laurus nobilis L. } \\
\text { Nectandra oppositifolia Nees } \\
\text { Ocotea pulchella (Nees \& Mart.) Mez } \\
\text { Persea americana Mill.* }\end{array}$ & $\begin{array}{l}\text { Canela-da-Indonésia } \\
\text { Louro } \\
\text { Canelo-ferrugem } \\
\text { Canela-guaicá } \\
\text { Abacate }\end{array}$ & $\begin{array}{l}\text { Ex } \\
\text { Ex } \\
\text { Nat } \\
\text { Nat } \\
\text { Ex }\end{array}$ & $\begin{array}{l}\text { Ex-BR } \\
\text { Ex-BR } \\
\text { Nat } \\
\text { Nat } \\
\text { Ex-BR }\end{array}$ \\
\hline $\begin{array}{l}\text { LILIACEAE (4) } \\
\text { Dracaena draco (L.) L. } \\
\text { Dracaena fragrans (L.) Ker Gawl. * } \\
\text { Dracaena marginata hort. } \\
\text { Yucca gigantea Lem. }\end{array}$ & $\begin{array}{l}\text { Planta-dragão } \\
\text { Dracena } \\
\text { Dracena } \\
\text { luca }\end{array}$ & $\begin{array}{l}\text { Ex } \\
\text { Ex } \\
\text { Ex } \\
\text { Ex }\end{array}$ & $\begin{array}{l}\text { Ex-BR } \\
\text { Ex-BR } \\
\text { Ex-BR } \\
\text { Ex-BR }\end{array}$ \\
\hline $\begin{array}{l}\text { LINNAEACEAE (1) } \\
\text { Abelia gracilenta W. W. Sm. }\end{array}$ & Abélia & Ex & Ex-BR \\
\hline $\begin{array}{l}\text { GENTIANACEAE (1) } \\
\text { Anthocleista grandiflora Gilg }\end{array}$ & Árvore-couve & Ex & Ex-BR \\
\hline $\begin{array}{l}\text { LYTHRACEAE (2) } \\
\text { Lafoensia pacari A. St.-Hil. } \\
\text { Lagerstroemia indica L. }\end{array}$ & $\begin{array}{l}\text { Dedaleiro } \\
\text { Extremosa }\end{array}$ & $\begin{array}{l}\text { Nat } \\
\text { Ex }\end{array}$ & $\begin{array}{l}\text { Ex-Nat } \\
\text { Ex-BR }\end{array}$ \\
\hline $\begin{array}{l}\text { MAGNOLIACEAE (1) } \\
\text { Magnolia grandiflora L. }\end{array}$ & Magnólia & Ex & Ex-BR \\
\hline $\begin{array}{l}\text { MALVACEAE (10) } \\
\text { Abutilon pictum (Gillies ex Hook.) Walp. } \\
\text { Ceiba speciosa (A. St.-Hil.) Ravenna } \\
\text { Dombeya wallichii (Lindl.) K. Schum. } \\
\text { Hibiscus rosa-sinensis L. } \\
\text { Hibiscus schizopetalus (Dyer) Hook. f. } \\
\text { Luehea divaricata Mart. \& Zucc. } \\
\text { Malvaviscus arboreus Cav. } \\
\text { Pachira aquatica Aubl. } \\
\text { Pachira glabra Pasq. } \\
\text { Sida rhombifolia L. }\end{array}$ & $\begin{array}{l}\text { Lanterna-chinesa } \\
\text { Paineira } \\
\text { Astrapéia } \\
\text { Hibisco } \\
\text { Hibisco-crespo } \\
\text { Açoita-cavalo } \\
\text { Malvavisco } \\
\text { Monguba } \\
\text { Cacau selvagem } \\
\text { Guanxuma }\end{array}$ & $\begin{array}{l}\text { Ex } \\
\text { Nat } \\
\text { Ex } \\
\text { Ex } \\
\text { Ex } \\
\text { Nat } \\
\text { Ex } \\
\text { Nat } \\
\text { Nat } \\
\text { Nat }\end{array}$ & $\begin{array}{l}\text { Ex-BR } \\
\text { Ex-PR } \\
\text { Ex-BR } \\
\text { Ex-BR } \\
\text { Ex-BR } \\
\text { Ex-Nat } \\
\text { Ex-BR } \\
\text { Ex-PR } \\
\text { Ex-PR } \\
\text { Nat }\end{array}$ \\
\hline $\begin{array}{l}\text { MALPHIGIACEAE (2) } \\
\text { Bunchosia armeniaca (Cav.) DC. } \\
\text { Malpighia emarginata DC. }\end{array}$ & $\begin{array}{l}\text { Ciriguela } \\
\text { Acerola }\end{array}$ & $\begin{array}{l}\text { Ex } \\
\text { Ex }\end{array}$ & $\begin{array}{l}\text { Ex-BR } \\
\text { Ex-BR }\end{array}$ \\
\hline $\begin{array}{l}\text { MELASTOMATACEAE (3) } \\
\text { Tibouchina granulosa (Desr.) Cogn. } \\
\text { Tibouchina heteromalla (D. Don) Cogn. } \\
\text { Tibouchina pulchra Cogn. }\end{array}$ & $\begin{array}{l}\text { Quaresmeira } \\
\text { Orelha-de-onça } \\
\text { Jacatirao }\end{array}$ & $\begin{array}{l}\text { Nat } \\
\text { Nat } \\
\text { Nat }\end{array}$ & $\begin{array}{l}\text { Ex-PR } \\
\text { Nat } \\
\text { Nat }\end{array}$ \\
\hline $\begin{array}{l}\text { MELIACEAE (2) } \\
\text { Cedrela fissilis Vell. } \\
\text { Melia azedarach L. * }\end{array}$ & $\begin{array}{l}\text { Cedro } \\
\text { Cinamomo }\end{array}$ & $\begin{array}{l}\text { Nat } \\
\text { Ex }\end{array}$ & $\begin{array}{l}\text { Ex-Nat } \\
\text { Ex-BR }\end{array}$ \\
\hline $\begin{array}{l}\text { MORACEAE (8) } \\
\text { Artocarpus heterophyllus Lam.* } \\
\text { Ficus benjamina L. } \\
\text { Ficus carica L. } \\
\text { Ficus celebensis Corner } \\
\text { Ficus elastica Roxb. ex Hornem. } \\
\text { Ficus Iuschnathiana (Miq.) Miq. }\end{array}$ & $\begin{array}{l}\text { Jaca } \\
\text { Figueira-benjamin } \\
\text { Figo } \\
\text { Figueira } \\
\text { Falsa-seringueira } \\
\text { Figueira }\end{array}$ & $\begin{array}{l}\text { Ex } \\
\text { Ex } \\
\text { Ex } \\
\text { Ex } \\
\text { Ex } \\
\text { Nat }\end{array}$ & $\begin{array}{l}\text { Ex-BR } \\
\text { Ex-BR } \\
\text { Ex-BR } \\
\text { Ex-BR } \\
\text { Ex-BR } \\
\text { Nat }\end{array}$ \\
\hline
\end{tabular}




\begin{tabular}{|c|c|c|c|}
\hline $\begin{array}{l}\text { FAMILIA ( } n \text { o de espécies) } \\
\text { Espécie }\end{array}$ & Nome Popular & DGFP & DGCE \\
\hline $\begin{array}{l}\text { Ficus organensis (Miq.) Miq. } \\
\text { Morus nigra L. * }\end{array}$ & $\begin{array}{l}\text { Figueira } \\
\text { Amora }\end{array}$ & $\begin{array}{l}\text { Nat } \\
\text { Ex }\end{array}$ & $\begin{array}{l}\text { Nat } \\
\text { Ex-BR }\end{array}$ \\
\hline $\begin{array}{l}\text { MYRTACEAE (10) } \\
\text { Eucalyptus sp. } \\
\text { Eugenia brasiliensis Lam. } \\
\text { Eugenia involucrata DC. } \\
\text { Eugenia uniflora L. } \\
\text { Myrcia ilheosensis Kiaersk. } \\
\text { Plinia edulis (Vell.) Sobral } \\
\text { Psidium cattleianum Sabine } \\
\text { Psidium guajava L. * } \\
\text { Syzygium cumini (L.) Skeels * } \\
\text { Syzygium jambos (L.) Alston * }\end{array}$ & $\begin{array}{l}\text { Eucalipto } \\
\text { Grumixama } \\
\text { Cereja } \\
\text { Pitanga } \\
\text { Guamirim } \\
\text { Cambucá } \\
\text { Araçá } \\
\text { Goiaba } \\
\text { Guapế } \\
\text { Jambo }\end{array}$ & $\begin{array}{l}\text { Ex } \\
\text { Nat } \\
\text { Nat } \\
\text { Nat } \\
\text { Nat } \\
\text { Nat } \\
\text { Nat } \\
\text { Ex } \\
\text { Ex } \\
\text { Ex }\end{array}$ & $\begin{array}{l}\text { Ex-BR } \\
\text { Nat } \\
\text { Ex-Nat } \\
\text { Nat } \\
\text { Nat } \\
\text { Nat } \\
\text { Nat } \\
\text { Ex-BR } \\
\text { Ex-BR } \\
\text { Ex-BR }\end{array}$ \\
\hline $\begin{array}{l}\text { NYCTAGINACEAE (2) } \\
\text { Bougainvillea glabra Choisy } \\
\text { Bougainvillea spectabilis Willd. }\end{array}$ & $\begin{array}{l}\text { Primavera } \\
\text { Primavera }\end{array}$ & $\begin{array}{l}\text { Nat } \\
\text { Nat }\end{array}$ & $\begin{array}{l}\text { Ex-Nat } \\
\text { Ex-Nat }\end{array}$ \\
\hline $\begin{array}{l}\text { OLEACEAE (1) } \\
\text { Ligustrum lucidum W. T. Aiton * }\end{array}$ & Alfeneiro & Ex & Ex-BR \\
\hline $\begin{array}{l}\text { OXALIDACEAE }(1) \\
\text { Averrhoa carambola L. }\end{array}$ & Carambola & Ex & Ex-BR \\
\hline $\begin{array}{l}\text { PANDANACEAE (1) } \\
\text { Pandanus odorifer (Forssk.) Kuntze }\end{array}$ & Padano-perfumado & Ex & Ex-BR \\
\hline $\begin{array}{l}\text { PERACEAE (1) } \\
\text { Pera glabrata (Schott) Poepp. ex Baill. }\end{array}$ & Tabocuva & Nat & Nat \\
\hline $\begin{array}{l}\text { PINACEAE (2) } \\
\text { Pinus elliotti Engelm * } \\
\text { Pinus taeda L. * }\end{array}$ & $\begin{array}{l}\text { Pinus } \\
\text { Pinus }\end{array}$ & $\begin{array}{l}\text { Ex } \\
\text { Ex }\end{array}$ & $\begin{array}{l}\text { Ex-BR } \\
\text { Ex-BR }\end{array}$ \\
\hline $\begin{array}{l}\text { PIPERACEAE (1) } \\
\text { Piper aduncum L. }\end{array}$ & Falso-jaborandi & Nat & Nat \\
\hline $\begin{array}{l}\text { PODOCARPACEAE (1) } \\
\text { Podocarpus macrophyllus (Thunb.) Sweet }\end{array}$ & Pinheiro-budista & Ex & Ex-BR \\
\hline $\begin{array}{l}\text { POLYGONACEAE (1) } \\
\text { Triplaris caracasana Cham. }\end{array}$ & Pau-de-formiga-de-caracas & Ex & Ex-BR \\
\hline $\begin{array}{l}\text { PROTEACEAE (1) } \\
\text { Grevillea robusta A. Cunn. ex R. Br. }{ }^{*}\end{array}$ & Grevilha & Ex & Ex-BR \\
\hline $\begin{array}{l}\text { RHAMNACEAE (1) } \\
\text { Hovenia dulcis Thunb. }{ }^{*}\end{array}$ & Uva-do-japão & Ex & Ex-BR \\
\hline $\begin{array}{l}\text { RUBIACEAE (1) } \\
\text { Ixora chinensis Lam. }\end{array}$ & Ixora & Ex & Ex-BR \\
\hline $\begin{array}{l}\text { ROSACEAE (5) } \\
\text { Eriobotrya japonica (Thunb.) Lindl. * } \\
\text { Prunus campanulata Maxim. } \\
\text { Prunus serrulata Lindl. } \\
\text { Rosa x grandiflora Hort. } \\
\text { Rubus rosifolius Sm. }\end{array}$ & $\begin{array}{l}\text { Ameixa } \\
\text { Cerejeira-do-japão } \\
\text { Cerejeira-branca } \\
\text { Roseira } \\
\text { Amora-brava }\end{array}$ & $\begin{array}{l}\text { Ex } \\
\text { Ex } \\
\text { Ex } \\
\text { Ex } \\
\text { Nat }\end{array}$ & $\begin{array}{l}\text { Ex-BR } \\
\text { Ex-BR } \\
\text { Ex-BR } \\
\text { Ex-BR } \\
\text { Nat }\end{array}$ \\
\hline $\begin{array}{l}\text { RUTACEAE (2) } \\
\text { Citrus } \times \text { aurantium L. } \\
\text { Citrus limon (L.) Osbeck * }\end{array}$ & $\begin{array}{l}\text { Laranja-azeda } \\
\text { Limão }\end{array}$ & $\begin{array}{l}\text { Ex } \\
\text { Ex }\end{array}$ & $\begin{array}{l}\text { Ex-BR } \\
\text { Ex-BR }\end{array}$ \\
\hline $\begin{array}{l}\text { SALICACEAE (1) } \\
\text { Salix babylonica L. }\end{array}$ & Chorão & Ex & Ex-BR \\
\hline $\begin{array}{l}\text { SAPINDACEAE (1) } \\
\text { Koelreuteria paniculata Laxm. }\end{array}$ & Saboeiro & Ex & Ex-BR \\
\hline $\begin{array}{l}\text { SAPOTACEAE (3) } \\
\text { Chrysophyllum cainito L. } \\
\text { Mimusops balata (Aubl.) C. F. Gaertn. } \\
\text { Pouteria campechiana (Kunth) Baehni }\end{array}$ & $\begin{array}{l}\text { Abiu } \\
\text { Abricó-de-praia } \\
\text { canistel }\end{array}$ & $\begin{array}{l}\text { Nat } \\
\text { Ex } \\
\text { Ex }\end{array}$ & $\begin{array}{l}\text { Ex-BR } \\
\text { Ex-BR } \\
\text { Ex-BR }\end{array}$ \\
\hline $\begin{array}{l}\text { SOLANACEAE (5) } \\
\text { Acnistus arborescens (L.) Schltdl. } \\
\text { Brugmansia suaveolens (Humb. \& Bonpl. ex Willd.) Bercht. \& J. Presl } \\
\text { Brunfelsia uniflora (Pohl) D. Don } \\
\text { Solanum paniculatum L. } \\
\text { Solanum pseudoquina A. St.-Hil }\end{array}$ & $\begin{array}{l}\text { Fruto-de-sábia } \\
\text { Trombeteira } \\
\text { Manacá } \\
\text { Jurubeba } \\
\text { Quineira }\end{array}$ & $\begin{array}{l}\text { Nat } \\
\text { Nat } \\
\text { Nat } \\
\text { Nat } \\
\text { Nat }\end{array}$ & $\begin{array}{l}\text { Nat } \\
\text { Ex-PR } \\
\text { Ex-Nat } \\
\text { Nat } \\
\text { Nat }\end{array}$ \\
\hline
\end{tabular}




\begin{tabular}{|c|c|c|c|}
\hline $\begin{array}{l}\text { FAMILIA ( } n \text { ㅇe espécies) } \\
\text { Espécie }\end{array}$ & Nome Popular & DGFP & DGCE \\
\hline $\begin{array}{l}\text { STRELITZIACEAE (1) } \\
\text { Ravenala madagascariensis Sonn. }\end{array}$ & Árvore do viajante & Ex & Ex-BR \\
\hline $\begin{array}{l}\text { THEACEAE (1) } \\
\text { Camellia japonica L. }\end{array}$ & Camélia & Ex & Ex-BR \\
\hline $\begin{array}{l}\text { URTICACEAE (3) } \\
\text { Cecropia pachystachya Trécul } \\
\text { Coussapoa microcarpa (Schott) Rizzini } \\
\text { Urera baccifera (L.) Gaudich. ex Wedd. }\end{array}$ & $\begin{array}{l}\text { Embaúva } \\
\text { Figueira-mata-pau } \\
\text { Urtiga }\end{array}$ & $\begin{array}{l}\text { Nat } \\
\text { Nat } \\
\text { Nat }\end{array}$ & $\begin{array}{l}\text { Nat } \\
\text { Nat } \\
\text { Nat }\end{array}$ \\
\hline $\begin{array}{l}\text { VERBENACEAE (3) } \\
\text { Duranta erecta L. } \\
\text { Lantana camara L. } \\
\text { Vitex megapotamica (Spreng.) Moldenke }\end{array}$ & $\begin{array}{l}\text { Violeteira } \\
\text { Camara } \\
\text { Tarumã }\end{array}$ & $\begin{array}{l}\text { Nat } \\
\text { Nat } \\
\text { Nat }\end{array}$ & $\begin{array}{l}\text { Ex-PR } \\
\text { Nat } \\
\text { Ex-Nat }\end{array}$ \\
\hline
\end{tabular}

Nota: DGFP - Distribuição geográfica por fronteira política, Ex - exótica, Nat - Nativa. DGCE - distribuição Geográfica por Critério Ecológico, Nat - Nativa, Ex-NAT - Exótica Extra Ecossistema de Floresta Ombrófila Densa das Terras Baixas e Formações Pioneiras, Ex-PR - Exótica Extra Ecossistema Paranaense Ex-BR - Exótica Extra Ecossistema Brasileiros. * Espécie Exótica Invasora.

As famílias que apresentaram maior número de espécies foram Fabaceae (30 espécies), Areacaceae (13 espécies), Euphorbiaceae, Malvaceae e Myrtaceae (10 espécies cada), Bignociaceae e Moraceae (8 espécies cada) e Apocynaceae (7 espécies) (Figura 2), juntas essas 8 famílias correspondem com 48,5\% (96 espécies) da riqueza amostrada.

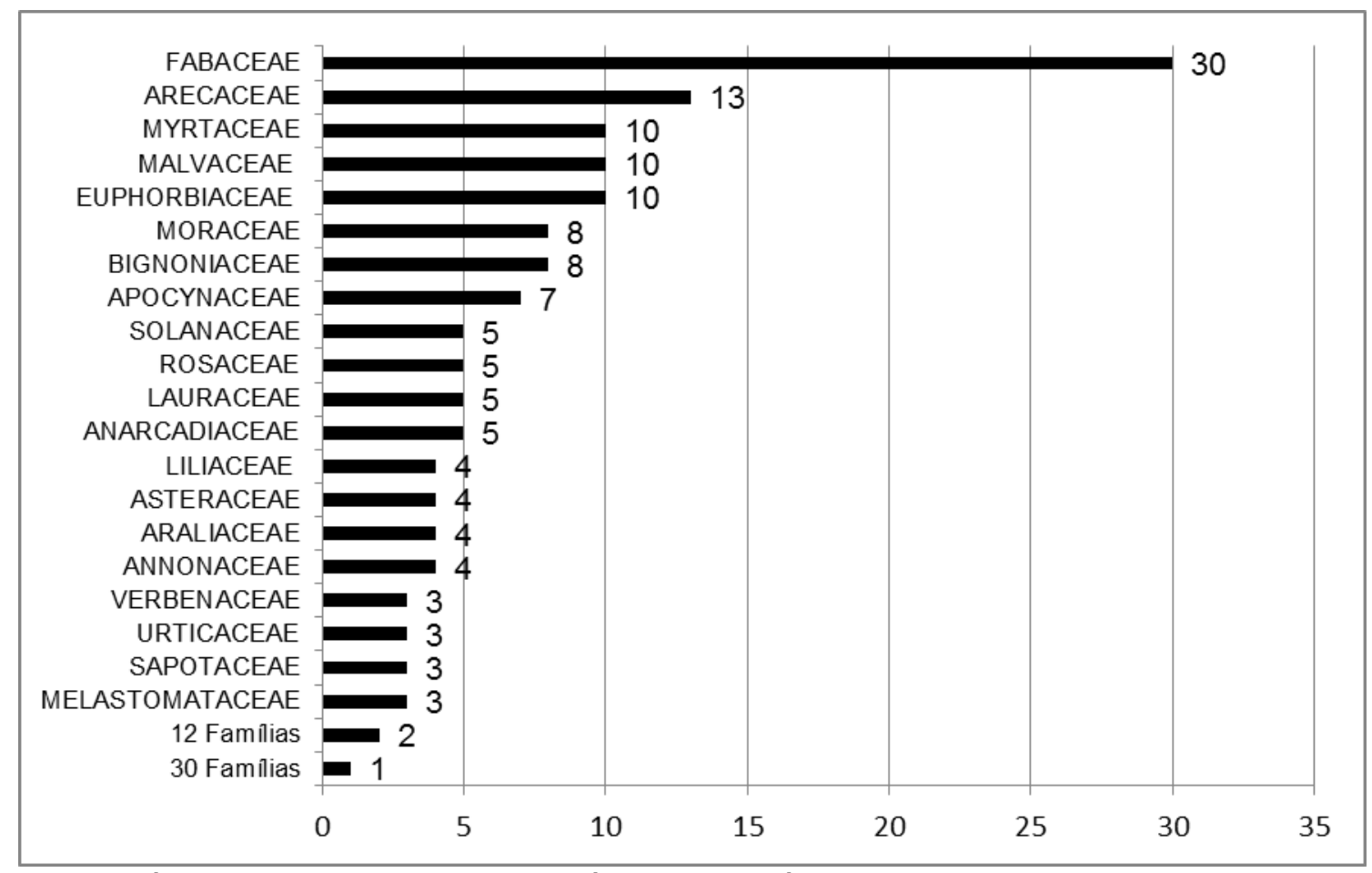

Figura 2. Famílias que apresentaram maior número de espécies

Figure 2. Families with higher number of species

As famílias Arecaceae, Bignoniaceae, Fabaceae e Myrtaceae também apresentaram elevada riqueza nos trabalhos de Blum, Borgo e Sampaio (2008), Silva, Silveira e Teixeira (2008), Richter et al. (2012). As espécies das famílias citadas anteriormente apresentam características morfológicas que proporcionam o seu uso na arborização viária urbana, por 
exemplo, as espécies da família Arecaceae possui padrão de copa e tronco singular, resultando em uma beleza diferenciada de outras famílias botânicas. As espécies da família Bignoniaceae apresentam flores vistosas e as famílias Fabaceae e Myrtaceae apresentam grande diversidade de espécies, geralmente geram frutos que são consumidos pela população, além da beleza proporcionada pela floração de algumas espécies.

Com relação ao método utilizado para distribuição geográfica utilizando fronteiras políticas e critério ecológico, ambos apresentaram resultados divergentes no que diz respeito às espécies exóticas e nativas.

O método para classificação das espécies por distribuição geográfica com fronteiras políticas (DGFP) indicou que no total das espécies amostradas, 56\% (109 espécies) são espécies exóticas, e as espécies nativas corresponderam com 44\% (87 espécies) do total amostrado (Figura 3).

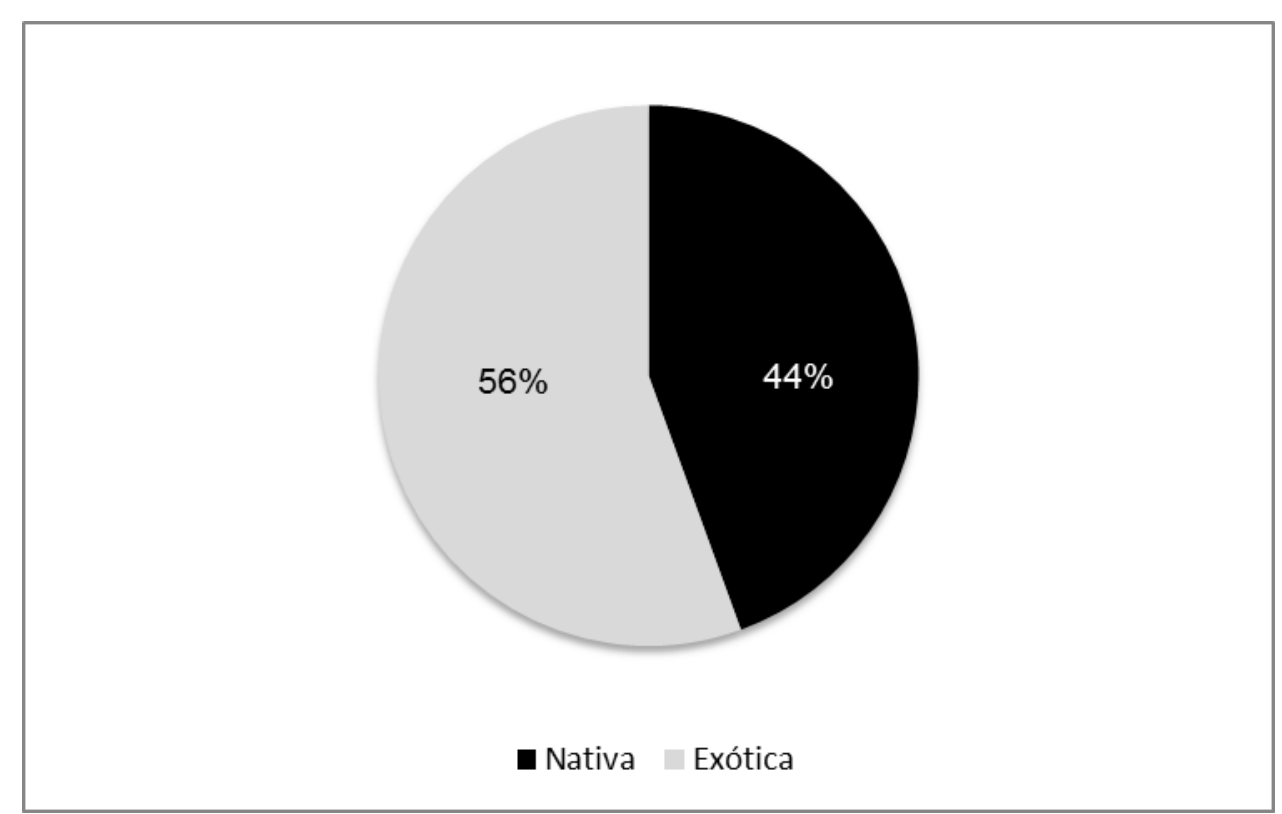

Figura 3. Espécies enquadradas segundo o critério de distribuição geográfica por fronteira política (DGFP)

Figure 3. Species classified according to criterion of geographical distribution by political frontier (DGFP)

Já o método para classificação das espécies por distribuição geográfica por critério ecológico (DGCE), as espécies Ex-BR resultaram 55\% (110 espécies) do total amostrado, as Ex-PR resultaram 12\% (23 espécies), as Ex-Nativa resultaram 11\% (21 espécies) e as espécies Nativas corresponderam com apenas 22\% (44 espécies) do total amostrado (Figura 4). 


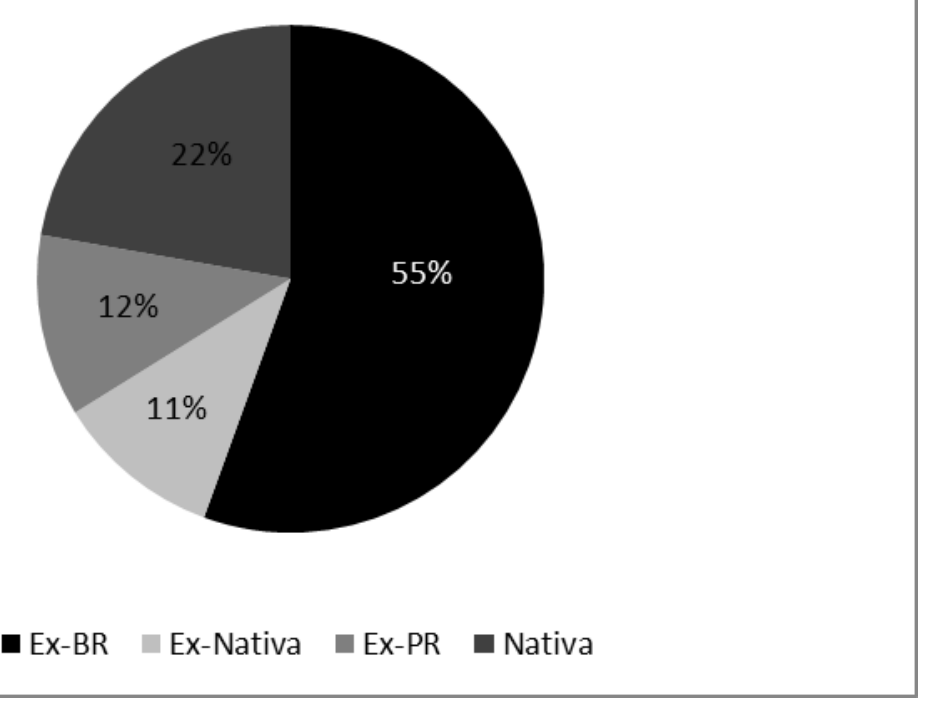

Figura 4. Espécies enquadradas segundo o critério de distribuição geográfica por critério ecológico (DGCE)

Figure 4. Species classified according to the criterion of geographic distribution by ecological criterion (DGCE)

Comparando os dois métodos de distribuição geográfica, o DGCE indicou que apenas 22\% (44 espécies) das espécies são nativas e 78\% (158 espécies) são exóticas, enquanto que o método DGFP indicou que 44\% (80 espécies) são nativas e 56\% (110 espécies) são exóticas.

Quando comparado o método de DGFP, o resultado do presente estudo mostrou similar aos resultados de Blum, Borgo e Sampaio (2008), registraram 55,2\% espécies exóticas e 44,8\% espécies nativas, Kramer e Krupek (2012) registraram 52\% de espécies exóticas e $48 \%$ de espécies nativas, Ferro et al. (2015) e Lima Neto et al. (2016) registraram 54\% de espécies exóticas e $46 \%$ de espécies nativas.

São escassos trabalhos que utilizam o critério ecológico, definindo a espécie nativa aquela que possui distribuição natural no local estudado, Biondi e Pedrosa-Macedo (2007) registram apenas $6,5 \%$ das espécies são oriundas de ecossistemas da cidade de Curitiba PR, Biondi e Leal (2008) ao caracterizar as plantas que são produzidas no horto da Barreirinha em Curitiba - PR registram apenas $26,67 \%$ das espécies são nativas dos ecossistemas ocorrentes na referida cidade, Blum, Borgo e Sampaio (2008) registraram 24,1\% espécies nativas da Floresta Estacional Semidecidual na arborização de vias públicas de Maringá - PR e Damo, Hefler e Jacobi (2015) ao realizarem um diagnóstico em vias públicas em dois bairros na cidade de Rio Grande - RS, registraram 69\% das espécies são exóticas e 31\% são espécies nativas.

O método DGCE mostrou ser mais robusto de ser usado para enquadramento da origem geográfica, pois evidência a realidade da distribuição geográfica de cada espécie no 
território estudado e também ser mais eficiente para políticas públicas, por exemplo, para o planejamento e manejo da arborização viária urbana. Blum, Borgo e Sampaio (2008) ressaltam que o critério tradicional (fronteiras políticas) pode dar uma falsa impressão da arborização que foi realizada em Maringá, pois apenas 31\% das árvores seriam consideradas exóticas, porém a realidade é que $81,5 \%$ das árvores existentes na arborização de vias públicas de Maringá são exóticas ao ecossistema que cobre a referida cidade.

As espécies nativas são de grande importância para arborização urbana, trazendo diversos benefícios, como a valorização da flora regional (BLUM; BORGO; SAMPAIO, 2008), desempenham funções ecológicas, como o fornecimento de alimento e abrigo à fauna, bemestar da população (MUNEROLI; MASCARÓ, 2010), contribuem com o potencial paisagístico de espécies autóctones, impedem que haja problemas relacionados com invasão biológica de espécies exóticas invasoras (BIONDI; MULLER, 2013), pensando em escala maior, as árvores nativas podem funcionar como corredores ecológicos, conectando a praças e parques (SZYMCZAK et al., 2012).

Com relação às espécies exóticas invasoras, do total das 198 espécies registradas, 24 (12\%) espécies são exóticas invasoras para o estado do Paraná: Aleurites moluccanus (L.) Willd. (noz-da-Índia), Artocarpus heterophyllus Lam. (jaca), Citrus limon (L.) Osbeck (limão), Dracaena fragrans (L.) Ker Gawl. (draceana), Eriobotrya japonica (Thunb.) Lindl. (ameixa), Grevillea robusta A. Cunn. ex R. Br. (grevilha), Hovenia dulcis Thunb. (uva-do-japão), Leucaena leucocephala (Lam.) de Wit (leucena), Ligustrum lucidum W. T. Aiton (alfeneiro), Mangifera indica L. (manga), Melia azedarach L. (cinamomo), Morus nigra L. (amora), Persea americana Mill. (abacate), Pinus elliotti Engelm (pinus), Pinus taeda L. (pinus), Psidium guajava L. (goiaba), Ricinus communis L. (mamona), Schefflera arboricola (Hayata) Merr. (cheflera), Senna macranthera (DC. ex Collad.) H. S. Irwin \& Barneby (chuva-de-ouro), Spathodea campanulata P. Beauv. (espatódea), Syzygium cumini L. (guapê), Syzygium jambos L. (jambo), Tecoma stans e Terminalia catappa L. (sombreiro).

As espécies citadas anteriormente apresentam diferentes formas de dispersão, sendo 17 (70,8\%) espécies por dispersão zoocórica e 7 (29,2\%) espécies por outros tipos de dispersão (anemocórica ou bacórica). Com relação a essas mesmas espécies, quando há dispersão associada às atividades humanas, 22 (91,6\%) espécies são introduzidas intencionalmente pelo ser humano e $2(8,4 \%)$ espécies não tem relação com as atividades humanas (INSTITUTO HORUS, 2016b).

Vários fatores contribuem para as plantas exóticas invasoras se estabelecerem, tais como a ausência de inimigos naturais, adaptar-se com maior facilidade a ambiente climático e ambientalmente similar à sua região de origem, dispersão por ventos, maturação precoce, longos períodos de floração e frutificação, crescimento rápido, adaptação a áreas degradadas, 
eficiência na dispersão de sementes e no sucesso reprodutivo. Essas espécies geram inúmeros problemas, como o empobrecimento de ecossistemas, risco de produzir híbridos devido o cruzamento com espécies nativas, impactos negativos para economia (INSTITUTO HORUS, 2016a).

Inúmeros países têm a sua economia prejudicada pela introdução de espécies exóticas invasoras, tais como Nova Zelândia, Austrália, África do Sul e Estados Unidos (BIONDI; PEDROSA-MACEDO, 2007). Na África do Sul, das 491 espécies exóticas, estima-se que a metade tenha sido introduzida para fins relacionados com atividades humanas, na Austrália estima-se que $65 \%$ das plantas naturalizadas no país nos últimos 25 anos tenham sido introduzidas para fins ornamentais, e na Nova Zelândia, das 24 mil espécies introduzidas, cerca de $70 \%$ são para fins ornamentais, sendo o número de espécies exóticas naturalizadas levemente superiores ao de espécies nativas (INSTITUTO HORUS, 2016a).

O registro de espécies exóticas nas cidades brasileiras é comum, vários fatores contribuem para que este fato ocorra, tais como a falta de preocupação das prefeituras com o planejamento da arborização (SILVA; SILVEIRA; TEIXEIRA, 2008), falta de informações sobre a flora brasileira e seu potencial paisagístico (SILVA; PERELLÓ, 2010), vantagens competitivas em relação às espécies nativas, estando livres de competidores, predadores e parasitas (INSTITUTO HORUS, 2016a).

$\mathrm{Na}$ cidade de Paranaguá é comum encontrar nas praças e nas calçadas das vias públicas as espécies exóticas, tais como Artocarpus heterophyllus, Ligustrum lucidum, Mangifera indica, Melia azedarach, Spathodea campanulata, Syzygium cumini e Terminalia catappa, o que aumenta o risco de introdução dessas espécies nos ambientes florestais adjacentes, principalmente em unidades de conservação, e também problemas relacionados à economia, com intuito de despender recurso financeiro para o manejo.

Além dos fatores citados por Silva, Silveira e Teixeira (2008), Silva e Perelló (2010) e Instituto Horus (2016a), outro fator que pode contribuir com a introdução de espécies exóticas é como a Botânica ou conhecimento da flora local é abordado no ensino fundamental e nos livros didáticos. Silva, Farina e Lourenço (2012), investigaram como que tem sido ensinada a botânica no litoral do Paraná, e evidenciaram que falta conhecimento sobre as plantas nativas da região, onde professores e alunos citaram as seguintes espécies como nativa: Artocarpus heterophyllus, Citrus limon, Mangifera indica, Melia azedarach, Morus nigra, Persea americana, Psidium guajava, Syzygium cumini, e Terminalia catappa.

Os mesmos autores citados acima, ainda evidenciaram o quanto a população desconhece as espécies nativas que estão ao seu redor, à falta do conhecimento técnico para saber a definição correta do conceito de espécie nativa e o quanto é preocupante, professores 
de Ciências terem dificuldade em saber qual espécie é nativa e consequentemente estar passando adiante uma informação errônea.

Como sugestão para o manejo adequado para arborização viária na cidade de Paranaguá, deve-se erradicar as espécies exóticas invasoras, substituir gradualmente as espécies exóticas por espécies nativas adotando critério ecológico utilizado neste trabalho, sendo espécies oriundas das formações vegetacionais da planície litorânea (Floresta Ombrófila Densa das Terras baixas e formações pioneiras).

\section{CONCLUSÃO}

Foram registradas 198 espécies, sendo as famílias com maior riqueza a Apocynaceae, Areacaceae, Bignociaceae, Euphorbiaceae, Fabaceae, Malvaceae, Moraceae e Myrtaceae, sendo que essas oito famílias correspondem com 48,5\% (96 espécies) da riqueza amostrada. Do total das 198 espécies registradas pelo presente trabalho, 24 espécies são exóticas invasoras para o estado do Paraná.

O método para classificação das espécies por DGFP indicou que 56\% são espécies exóticas e 44\% são espécies nativas. Já o método para classificação das espécies por DGCE, as espécies Ex-BR resultaram 55\% do total amostrado, as Ex-PR corresponderam com 12\%, as Ex-Nativa resultaram $11 \%$ e as espécies Nativas resultaram em $22 \%$ do total. $O$ método DGCE mostrou-se ser mais correto de ser usado para enquadramento das espécies, pois evidência a realidade da distribuição geográfica de cada espécie no território estudado e também ser mais eficiente para políticas públicas, por exemplo, para o planejamento e manejo da arborização viária urbana.

\section{REFERÊNCIAS}

ANGIOSPERM PHYLOGENY GROUP. An update of the Angiosperm Phylogeny Group classification for the orders and families of flowering plants: APG III. Botanical Journal of the Linnean Society, Hoboken, v. 161, n. 2, p. 105-121, 2009.

BIONDI, D.; LEAL, L. Caracterização das plantas produzidas no Horto Municipal da Barreirinha - Curitiba/PR. Revista da Sociedade Brasileira de Arborização Urbana, Piracicaba, v. 3, n. 2, p. 20-36, 2008.

BIONDI, D.; MULLER, E. Espécies arbóreas invasoras no paisagismo dos parques urbanos de Curitiba, PR. Floresta, Curitiba, v. 43, n. 1, p. 69-82, 2013. 
BIONDI, D.; PEDROSA-MACEDO, J. H. Plantas invasoras encontradas na área urbana de Curitiba (PR). Floresta, Curitiba, v. 38, n. 1, p. 129-144, 2008.

BLUM, C. T.; BORGO, M.; SAMPAIO, A. C. F. Espécies exóticas invasoras na arborização de vias públicas de Maringá-PR. Revista da Sociedade Brasileira de Arborização Urbana, Piracicaba, v.3, n.2, p.78-97, 2008.

DAMO, A.; HEFLER, S. M.; JACOBI, U. S. Diagnóstico da arborização em vias públicas dos bairros cidade nova e centro na cidade de Rio Grande - RS. Revista da Sociedade Brasileira de Arborização Urbana, Piracicaba, v. 10, n. 1, p. 43-60, 2015.

FARIA, J. L. G.; MONTEIRO, E. A.; FISCH, S. T. V. Arborização de vias públicas do município de Jacareí - SP. Revista da Sociedade Brasileira de Arborização Urbana, Piracicaba, v. 2, n. 4, p. 20-33, 2007.

FERRO, C. C. S.; OLIVEIRA, R. S.; ANDRADE, F. W. C.; SOUZA, S. M. A. R. Inventário qualiquantitativo da arborização viária de um trecho da rodovia PA-275 no município de Parauapebas-PA. Revista da Sociedade Brasileira de Arborização Urbana, Piracicaba, v. 10, n. 3, p. 73-84, 2015.

INSTITUTO AGRONÔMICO DO PARANÁ (IAPAR). Médias históricas em estações do IAPAR. Disponível em: http://www.iapar.br/modules/conteudo/conteudo.php?conteudo $=1070$. Acesso em: 01 jan. 2016.

INSTITUTO AMBIENTAL DO PARANÁ (IAP). Portaria IAP no 59 de 15 de abril de 2015 "Lista de Espécies Exóticas Invasoras do Estado do Paraná". Disponível em: <http://www.iap.pr.gov.br/modules/noticias/article.php?storyid=705>. Acesso em: 15 jun. 2016.

INSTITUTO HÓRUS DE DESENVOLVIMENTO E CONSERVAÇÃO AMBIENTAL. O Processo de Degradação Ambiental Originado por Plantas Exóticas Invasoras. Disponível em:< http://www.institutohorus.org.br/download/midia/ambbr2.htm>. Acesso em: 11 jun. 2016a.

INSTITUTO HÓRUS DE DESENVOLVIMENTO E CONSERVAÇÃO AMBIENTAL. I3N. Disponível em:< http://i3n.institutohorus.org.br/www/?p =YGxIJnA 4ZTQxPm MidR M Y UIRZLHore3FuPHoiaT0EA0UUAwMSQFEYHxoaRxJED2gzNjQxMWZjOSYgM3creio4O2lhdjxo a24\%2BbzANHE5IFBofGVkMWI8\%3D >. Acesso em: 11 jun. $2016 \mathrm{~b}$.

INTERNATIONAL UNION FOR CONSERVATION OF NATURE (IUCN). Guidelines for the prevention of biodiversity loss caused by alien invasive species. Disponível em: <https://portals.iucn.org/library/efiles/edocs/Rep-2000-052.pdf. Acesso em: 21 jun. 2016.

JARDIM BOTÂNICO DO RIO DE JANEIRO (JBRJ). Flora do Brasil. Disponível em: $<$ http://floradobrasil.jbrj.gov.br/reflora/listaBrasil/PrincipalUC/PrincipalUC.do\#CondicaoTaxonCP >. Acesso em: 20 jun. 2016.

KRAMER, J. A.; KRUPEK, R. A. Caracterização florístiça e ecológica da arborização de praças públicas do município de Guarapuava, PR. Revista Árvore, Viçosa, v. 36, n. 4, p. 647-658, 2012.

MACHADO, R. R. B.; MEUNIER, I. M. J.; SILVA, J. A. A.; CASTRO, A. A. J. F. Árvores nativas para a arborização de Teresina, Piauí. Revista da Sociedade Brasileira de Arborização Urbana, Piracicaba, v. 1, n. 1, p. 10-18. 2006. 
MUNEROLI, C, C.; MASCARÓ, J, J. Arborização Urbana: Uso de Espécies Arbóreas Nativas na Captura do Carbono Atmosférico. Revista da Sociedade Brasileira de Arborização Urbana, Piracicaba, v. 5, n. 1, p. 160-182, 2010.

LIMA NETO, E. M. de; BIONDI, D.; LEAL, L.; SILVA, F. L. R.; PINHEIRO, F. A. P. Análise da composição florística de Boa Vista-RR: subsídio para a gestão da arborização de ruas. Revista da Sociedade Brasileira de Arborização Urbana, Piracicaba, v. 11, n. 1, p. 58-72, 2016.

RICHTER, C.; PEITER, M. X.; ROBAINA, A. D.; SOUZA, A. R. C.; FERRAZ, R. C.; DAVID, A. F. Levantamento da arborização urbana pública de mata/RS. Revista da Sociedade Brasileira de Arborização Urbana. Piracicaba, v. 7, n. 3, p. 88-96, 2012.

SANTOS, C. Z. A.; FERREIRA, R. A.; SANTOS, L. R.; SANTOS, L. I.; GOMES, S. H.; GRAÇA, $\mathrm{D}, \mathrm{A}$. S. Análise qualitativa da arborização urbana de 25 vias públicas da cidade de Aracaju-SE. Ciência Florestal, Santa Maria, v. 25, n. 3, p. 751-763, 2015.

SILVA, M. D. M.; SILVEIRA, R. P.; TEIXEIRA, M. I. J. G. Avaliação da arborização de vias públicas de uma área da região oeste da cidade de Franca/SP. Revista da Sociedade Brasileira de Arborização Urbana, Piracicaba, v. 3, n. 1, p. 19-35, 2008.

SILVA, L. M.; FARINA, B.; LOURENÇO, J. F. F. O ensino de botânica no litoral do Paraná e as implicações da arborização urbana. Revista da Sociedade Brasileira de Arborização Urbana. Piracicaba, v. 7, n. 3, p. 97-103, 2012.

SILVA, J. G; PERELLÓ, L. F. C. Conservação de espécies ameaçadas do Rio Grande do Sul através de seu uso no paisagismo. Revista da Sociedade Brasileira de Arborização Urbana, Piracicaba, v. 5, n. 4, p. 01-21, 2010.

SZYMCZAK, D. A.; BRUN, F. G. K.; BRUN, E. J.; NAVROSKI, M. C.; LONDERO, E. K. Arborização de vias públicas do bairro Camobi, Santa Maria, RS. Revista Eletrônica em Gestão, Educação e Tecnologia Ambiental, Cascavel, v. 8, n 8, p. 1611-1625, 2012.

THE PLANT LIST. The Plant List - a working list of all plant species. Disponível em: <http://www.theplantlist.org/. Acesso em: 21 jun. 2016. 